\title{
When Lay Knowledge is a Symptom: The Uses of Insight in Psychiatric Interventions
}

\author{
MARIE-PIER RIVEST \\ Université de Moncton, Canada
}

\begin{abstract}
In psychiatry, the concept of "insight" commonly refers to a patient's judgment that they have a mental illness and need clinical treatment. However, this concept has been criticized because it imposes psychiatric knowledge on the subjective experiences of mental illness and possible interventions. A significant body of literature is critical of mental health interventions; however, insight remains underexplored in this realm. This paper adds to critical analyses of insight by exploring how it is defined and deployed by mental health professionals in an acute inpatient mental health unit in a Canadian general hospital and what disciplinary and epistemic effects it has on patients. To this end, I draw on Foucault's theories of psychiatric power and Fricker's concept of epistemic injustice to analyze results from an ethnographic study conducted in an inpatient mental health unit. The results show how patients' resistance to medical compliance is framed by staff as a lack of insight, which reinforces the psychiatric model of mental illness.
\end{abstract}

KEYWORDS mental health; Fricker; Foucault; ethnography; qualitative; psychiatry; social work

\section{Deinstitutionalization, Individualization and Contemporary Mental Health Services}

In North America, the deinstitutionalization of mental health services in the mid-to-late $20^{\text {th }}$ century instigated crucial changes in mental health service planning and delivery. This process led to the closure of many psychiatric institutions, the transfer of patients to general hospitals, and a commitment to reinvest resources in community-based care interventions that centre on psychosocial readaptation and recovery (Klein et al., 2018; Sealy \& Whitehead, 2004). However, this shift has been challenging. Despite the change in mental health services away from hospitals, the medical/psychiatric model remains predominant in community-based care framings of mental health, illness, and treatment (Roy et al., 2017). Consequently, 
deinstitutionalization freed psychiatry from the asylum walls, but attached it to other mental health interventions (Klein et al., 2018). This process has been enabled by the medicalization of social distress (Conrad, 2005) and the psychologization of social interactions (Roy et al., 2017).

In the context of institutional mental health practice, and due to organizational constraints, the tendencies described above entail specific consequences. Notably, practitioners are more inclined to provide short-term, solution-focused interventions that bypass the more challenging process of rearranging social structures that contribute to social injustice and associated mental distress (Khoury \& Rodriguez del Barrio, 2015; Rivest \& Moreau, 2015). The notion of "recovery" (Anthony, 1993; Deegan, 2003), for instance, has become a pillar in many institutional and community mental health services. Its predominant vision is focused on the individual, encouraging self-management and self-improvement, two notions imbricated in contemporary neoliberal social relations (Roy, 2019).

The individualization of mental health and illness can be linked to psychocentrism (Rimke, 2018; Rimke \& Brock, 2012), a concept critical of the predominance of the biomedical model that locates "mental and emotional distress" (Rimke, 2018, p. 17) within the individual and promotes individual solutions to problems that are often rooted in structural injustices. It could be argued that on a structural level, psychocentrism elevates saneness as a normative ideal, contributing to what Procknow (2018, p. 1166) calls "sane supremacy," a society in which saneness is seen as the norm, thereby othering and marginalizing individuals perceived as insane and legitimizing various types of sanctions (medical, legal, social, etc.) against them (LeBlanc $\&$ Kinsella, 2016). These reflections, however, remain incomplete if we omit the role of racism and white supremacy in fuelling these social forces. To this point, Joseph (2015) explains that "psy" disciplines are "complicit in the formations and advancement of a normative subject (often centered as a White, Christian, able-bodied, able-minded, heterosexual, cis-gendered male $[\ldots]) "$ (p. 35). Critiques of the mental health system and interventions including the present paper - must then be understood as critiques of their raced, gendered, abled, and sexed dynamics and outcomes.

Given this context of individualization, psychocentrism, and white-malesane supremacy, it is relevant to reflect on contemporary figures of patienthood in mental health service provision. More than ever, psychiatric patients are required by practitioners to exhibit signs of autonomy, initiative, and personal responsibility during their treatment and recovery. In previous work (Rivest, 2017), I describe how hospital staff and patients understand the meaning of "patient" in two Canadian mental health service institutions: an inpatient psychiatric unit in a general hospital and a client advisory council of a tertiary mental health institution. In this paper, I add to critical examinations of mental health services by focusing on the concept of insight, exploring how it is mobilized explicitly and implicitly by members of the hospital staff and patients themselves. I demonstrate how this concept contributes to the 
ordering of social interactions and the disciplinary construction of an "ideal" patient, who is characterized by autonomy and personal responsibility expressed through compliance and agreement with psychiatric explanations of mental illness. These processes legitimize psychiatry as the dominant framework for understanding mental distress, and at the same time delegitimize disagreement and dissent from this perspective (Diesfeld \& Sjöström, 2007).

My argument unfolds in four sections. I first define insight and review the literature on the concept. I then develop a conceptual framework, including the work of Foucault (1979) and Fricker (2007), which enables me to critically reflect on the uses of insight in the inpatient mental health unit. In the third section, I provide methodological details about this critical ethnography. Fourth, I present my analysis in the form of four vignettes that illustrate how insight serves to discipline patients and coerce them, to varying degrees, into accepting the psychiatric model. I conclude with reflections on the need for further critical inquiries on insight.

\section{Psychiatric Definitions of Insight}

The concept of insight originates from Greek philosophers' interest in selfknowledge and is associated with more recent notions of introspection and lucidity (Marková, 2005). Insight made its debut in psychiatry at the beginning of the 19th century, when alienists began to integrate into the diagnostic process patients' assessments of their level of self-consciousness about their mental illness, which signifies a shift in the definition of madness and its relation to reason. Whereas "mad" individuals were once understood to be devoid of reason, the founders of modern psychiatry documented varying degrees of madness, which implied variable degrees of reason. Pinel, for example, spoke of a "reasoning madness" (Marková, 2005, p. 5), a condition in which individuals experience extreme emotional states while preserving some awareness of their psychological state.

Insight crystallizes the relationship between reason and madness, which is evident in how it is defined. There are many definitions of insight (Marková \& Berrios, 1995; Mintz et al., 2003), but the concept encapsulates one or more of the following elements: "awareness of mental disorder, awareness of the social consequences of disorder, awareness of the need for treatment, awareness of symptoms of mental disorder and attribution of symptoms of mental disorder" (Mintz et al., 2003, p. 78). Other definitions include the ability to associate one's behaviours and beliefs to symptoms of a psychiatric disorder (David, 1990). Insight can be assessed on a continuum, ranging from a "complete" understanding of one's mental state and the need for treatment to a partial consciousness of one's diagnosis and relative inability to 
appreciate its implications. In cases of marked absence of insight, patients may be labelled delusional or irrational.

Insight is relational in two ways. First, insight does not exist in and of itself but always refers to an object: insight into one's symptoms, condition, need for treatment, etc. Second, insight is understood almost solely in the context of medico-psychiatric interactions. So, insight is an integral part of mental health assessments (Beck-Sander, 1998; Galasiński \& Opaliński, 2012; Guibet Lafaye, 2015). In other words, insight is produced during patient and clinician encounters rather than being a "fixed and objectively measurable trait" (Pilling et al., 2018, p. 196). Patients' perceptions are then measured by clinicians against the health-related observations of family and friends, while they consider the conditions and context in which patients were first brought to hospital. Finally, these observations are translated into psychiatric vocabulary to assess patients' levels of insight. Studies have associated insight impairment to poor treatment outcomes and adherence (Segarra et al., 2012) and diminished help-seeking behaviour (Konstantakopoulos, 2019).

Despite the well-established use of insight in mental health interventions, a growing body of literature has begun to critique various aspects of its definition and use in clinical practice. Beck-Sander (1998) notes that insight lacks conceptual clarity. Insight can be associated with awareness of illness and compliance, but the extent to which these notions are central to the concept varies. The "interpretive flexibility" (Diesfeld \& Sjöström, 2007, p. 96) of insight can have implications at the practical level.

Hamilton and Roper (2006) call on mental health practitioners (nurses in particular) to reassess their reliance on the notion of insight. They challenge the taken-for-granted place that insight occupies in mental health interventions, explaining that professionals may come to different conclusions about an individual's level of insight based on what they know about the person and their background. The concept also leaves little room for patients' perspectives and may even imply "trust and gratitude for effective medical treatment” (Hamilton \& Roper, 2006, p. 420).

Others have noted that insight appears to be highly dependent on individuals' acceptance of the psychiatric model (Galasiński \& Opaliński, 2012). Research demonstrates that patients who agree with psychiatric explanations of their distress and comply with treatment are likely to be described by professionals as being more insightful than individuals who contest framings of their situation as the result of mental illness. For instance, Pilling et al. (2018) examine how relations of race, gender, class, and sexuality shape the uses of insight. They conclude that patients belonging to oppressed groups are more likely to be seen as lacking insight than socially privileged patients. Consequently, the confluence of racism, colonialism, sanism, and other systems of oppression must be integrated into a critical approach to psychiatric power (Joseph, 2015) and insight. After having outlined a general definition of insight and provided an overview of critiques of the concept, I now expand on the latter by presenting the theoretical 
orientations that animate this paper.

\section{Thinking Critically About Insight: Theoretical Anchors}

Critical perspectives on insight can be augmented by drawing on Foucault's views on psychiatric power and Fricker's (2007) concept of epistemic injustice. These elements can illuminate how insight is mobilized, and to what effects, in the professional-layperson relationship in a psychiatric context. Foucault (1979) asserts that modern western societies can be characterized as disciplinary, meaning that the institutional definition and surveillance of "normality" within a human population is a form of productive power that compels individuals to monitor and create themselves (and others) as socially "normal" subjects. Foucault (1979) uses the metaphor of Jeremy Bentham's Panopticon to illustrate how individuals constantly selfmonitor to perform socially intelligible subjectivities as proscribed by institutional authorities. In this context, specific institutional knowledges that delineate "normality" and "abnormality" are used to "refine and intensify the exercise of power" (Roberts, 2005, p. 35). Indeed, human science disciplines are imbricated in this production of knowledge about human beings and truths - or discourses - about what are considered normal and abnormal subjects. Individuals come to think, behave, and understand themselves in accordance with dominant discourses to constitute themselves as socially intelligible subjects, just as social institutions apply this knowledge to classify and control human populations. These processes constitute a generalized disciplinary society created through the operations of productive (rather than repressive) power.

Psychiatry and the broader mental health field have been characterized as social institutions that produce normalizing discourses (Perron et al., 2005; Rivest \& Moreau, 2015). They enable the production of normalized "psychiatric subjects" who can be diagnosed and treated by mental health professionals. These professionals produce and draw from a body of disciplinary knowledge that makes particular assumptions about mental (ab)normality (for example, through the DSM) that guide their psychiatric interventions. In this sense, psychiatric institutions can be understood as disciplinary spaces or carceral environments (Kilty \& Dej, 2018) in which individuals - or psychiatric subjects - are observed, assessed, and encouraged to participate in therapies and interventions so they are eventually able to regulate "their own conduct in accordance with the norms promoted by psychiatry" (Roberts, 2005, p. 36). We see here the use of coercive interventions typically found in carceral settings (Ben-Moshe, 2020; Fabris, 2011). 
In Psychiatric Power, Foucault (2006) explores confession as integral to the relation between the mental health professional and the psychiatric subject. He analyzes an encounter between famous psychiatrist Philippe Pinel and a patient who initially refuses Pinel's diagnosis and treatment proposal but eventually acquiesces and confesses his suffering before accepting to be treated: "and, when the scene succeeds, there must be a victory in both struggles, the victory of one idea over another, which must be at the same time the victory of the doctor's will over the patient's will" (Foucault, 2006, p. 11). Foucault (2006) conceives this scene as a power struggle between the psychiatric expert and the layperson, and insight and its assessment can be seen similarly. "Having insight" from a Foucauldian perspective is indissociable from accepting a psychiatric explanation of one's mental state. Judgment of one's insight can only be made through a professional's interpretation of the patient's expression of self-perception using medical language. In short, Foucault's (2006) discussion of psychiatric power allows us to understand a lack of insight as an individual moral fault attributable to madness or a flaw needing to be corrected through psychiatric interventions. These observations can be linked to psychocentrism (Rimke, 2018) and sane supremacy (Procknow, 2018), in that the patient's perception is reinterpreted within a biomedical framework and measured against a (classed, gendered, racialized, and sexualized) sane ideal.

Because insight implies a confrontation between two perspectives emanating from differing social positions, the concept of epistemic injustice (Fricker, 2007) is relevant to a critical examination of insight. While Foucault (1979) explores how institutional knowledge is imbricated in the exercise of power, Fricker (2007) emphasizes the effects of social positioning on the legitimization of an individual's knowledge. She defines epistemic injustice as "a wrong done to someone specifically in their capacity as a knower" (p. 1). While Fricker (2007) distinguishes two forms of epistemic injustice, I emphasize its primary form: testimonial injustice.

Testimonial injustice refers to situations in which "someone is wronged in their capacity as a giver of knowledge" (Fricker, 2007, p. 7). This is the "primary form" of epistemic injustice and occurs when, due to individual prejudice or structural arrangements, a speaker is granted less credence as a knower or epistemic agent (Fricker, 2007, p. 4). Fricker (2007) draws on the example of race to demonstrate how this social construct and associated harmful racial stereotypes are often used to discredit Black men's legal defences. In a similar analysis, Crichton et al. (2017) explain that the prevalence of negative stereotypes about mental illness can lead mental health professionals to question and discredit patients' accounts, even if their accounts are truthful from their own perspectives and positionalities. Being a psychiatric patient puts individuals at risk of being epistemically discredited, and the intersection of mental illness with other marginalized social identities can exacerbate testimonial injustice. 
For example, through their analysis of psychiatric charts, Pilling et al. (2018) demonstrate that when patients explain their mental health situations using spiritual or cultural trauma-based narratives (e.g., sexual violence), they are less likely to be perceived as insightful. Their results also show that poor insight could justify using coercive measures such as community treatment orders and involuntary hospitalization. These results can also be linked to the infantilization of psychiatrized people; they are viewed as children who are unable to express legitimate knowledge and not competent enough to make their own decisions (Mills \& LeFrançois, 2018). In a broader sense, Mills and LeFrançois (2018) explain that the metaphor of infantilization has been used in colonial projects to justify coercive actions against marginalized groups such as disabled people, racialized people, and people labelled as mentally ill. Insight can thus be understood in this context as a mechanism that upholds white saneness. Despite this body of research, the concept of epistemic injustice and Foucault's perspective on psychiatric power remain underutilized when thinking about insight. In the next section, I present the method that allowed me to analyze the uses of insight in an inpatient psychiatric unit.

\section{Exploring Patienthood to Understand the Uses of Insight}

Data presented here were collected as part of a larger critical ethnographic study (Madison, 2019; Thomas, 1993) that focuses on normative injunctions regarding patienthood in contemporary mental health services (Rivest, 2017). The research aims to understand and compare meanings and outcomes of the "career of the mental patient" (Goffman, 1968) by taking into account different power relations between staff and patients (Foucault, 1979) within two mental health services. I undertook the research from the positionality of a privileged white settler woman who studies mental health as an outsider to first-hand psychiatric experiences. My training in social work - a discipline in which care and control are inextricably linked to its past and present operations (Chapman \& Withers, 2019; Kelly \& Chapman, 2015) - renders me complicit in the social processes I critique. It is possible that these aspects of my identity encouraged some people to participate in my study but deterred others from doing so, and my methodology may contain weaknesses related to the dimensions in which I hold privilege. For instance, my identity may have attracted research participants who share a similar social positioning (such as race), but at the same time it may have discouraged others who may be mistrustful of my intentions as a white settler woman affiliated with the social work profession. My positioning may also hinder my attempts to grasp the extent of the confluence between sane supremacy and white supremacy in relation to insight and contemporary mental health 
interventions.

Critical ethnography reveals "broader social processes of control, taming, power imbalance and the symbolic mechanisms that impose one set of preferred meanings of behaviours over others" (Thomas, 1993, p. 9). I used this approach in a patient council in a tertiary mental health centre and an acute inpatient mental health unit in a general hospital. Because my argument sheds light on the inpatient unit, I describe the methods used concerning this specific site.

To understand how the hospital represents itself and what values it claims are central to its mission and actions, I surveyed relevant grey literature such as annual reports, bulletins, legal texts, pamphlets, and websites. While grey literature can offer initial insights on contextual elements, observation constitutes another common component of ethnography that allowed me to understand the role insight plays in the mental health unit. So for four months, I shadowed social workers in the hospital as they interacted with other staff members (e.g., psychiatrists, nurses, occupational therapists), patients, and their family members. I also followed them on morning rounds, witnessed discharge planning and follow-ups, and attended staff meetings, initial intake interviews, case conferences, and family and individual meetings.

After this observation period, I used a purposive volunteer sampling strategy to recruit interview participants from two groups. First, I employed a semi-directed interview methodology with three inpatient social workers and two managers - all white women ranging in age from 30 to 55 with university degrees in health, social services, or management - to understand their role in the unit, perceptions of their relationships with patients, and vision for mental health services. Second, I conducted approximately 90-minute semi-directed interviews with 15 people (three inpatient social workers, two managers, and 10 patients). I used purposive, volunteer sampling to recruit all participants. Two selection criteria were used: they had to have been hospitalized in the mental health unit and were able and willing to talk about their experiences in the mental health system, their relationship and interactions with staff and other patients, and their social network outside the hospital. All participants are white, which prevents me from considering how insight may be instrumentalized to serve sane supremacy (Procknow, 2018) alongside white supremacy. They range in age from 20 to 53 and had an average of 13 years of interaction with psychiatric services. At that time, nine of 10 participants were unemployed, on medical leave, or receiving unemployment assistance.

To solicit patient participation, I presented the study to a recreational group held weekly in the acute mental health unit. I was allowed a few minutes at the start of the group to explain the study's aims and the nature of participation, and to answer patients' questions about the research. Interested patients then contacted me after their discharge to schedule an interview. Patient participants received $\$ 25$ in cash. This recruiting method may have influenced the data collected (Kristensen \& Ravn, 2015), as staff chose which 
patients could attend this recreational group. Employees may have invited patients whom they felt were more suitable to participate in this study due to their mental stability and positive view of hospitalization. Indeed, while some participants held critical opinions of their experiences in the mental health unit - primarily related to coercive practices - overall views were positive.

I analyzed observational and interview data by writing up what Laplantine (2010) calls an ethnographic description containing descriptive and narrative devices. Thematic analysis (Braun \& Clarke, 2006) of the interviews and grey literature documents was conducted with NVivo 11. The themes identified were then integrated into the ethnographic description to write up the results.

Because the aims of the larger study did not include a focus on insight, there were no interview questions that promoted participants to speak about insight specifically. However, the relevance of insight emerged through my observational activities, and interview participants (both staff and patients) also evoked the concept explicitly and implicitly, for instance, when they discussed differing perceptions of their situations or defined patients' roles in the mental health unit.

In the next section, I conceptualize the mental health unit as a disciplinary space (Foucault, 1979) in which insight and other techniques are deployed to produce psychiatric subjects. Then I discuss staff's definition and uses of insight, which sets the stage for exploring four case vignettes I constructed from my observations and interviews. These vignettes exemplify four different patient relationships to insight.

\section{The Mental Health Unit as a Disciplinary Space}

An individual's journey through the inpatient mental health unit is regulated by a series of assessments that ensure they adhere to specific norms, which are required to achieve the goal of being discharged from the hospital. In this context, hospital staff (psychiatrists, nurses, social workers, etc.) are gatekeepers of patients' "progress" through the unit. They apply various techniques to reward or punish patients. Insight plays a crucial role in staff's assessment of patients' progress.

Patient assessment occurs in two wards, each with differing rules, security levels, and privileges. The south wing, a smaller section of the ward, is reserved for individuals deemed to be at risk of harming themselves or others. Psychiatrists and social workers initially evaluate most patients in this ward. It is locked, most personal belongings are confiscated, and patients have minimal visitation rights. Once their mental state has stabilized and they are no longer perceived as a risk, patients are transferred to the centre ward, in which they can circulate more freely, gain more privileges (taking breaks 
outside, having visitors, etc.), and participate in therapeutic activities such as arts and crafts, yoga, bowling (a privilege reserved for a small number of patients), etc. To be discharged, patients must participate in these activities, as well as adhere to their medication regimes.

In Discipline and Punish, Foucault (1979) explains that disciplinary institutions employ strategies that convince individuals to conform to specific norms such as these. Staff participants define and deploy insight in three main ways that indicate to patients what is expected of them. First, a social worker's definition of insight demonstrates how this concept is intimately linked to specific behaviours expected from patients. These behaviours include accepting treatment recommendations and taking their medication:

It's when someone acknowledges that they have a mental illness; on the one hand, they accept it on a certain level as well. Acknowledging and accepting are two different things. So, insight is what brings someone to accept our team's recommendations, like medication, taking medication, and accepting follow-ups: seeing their general practitioner, their psychiatrist, seeing their CMHA [Canadian Mental Health Association] worker, working with them. And understanding that's another criterion as well - that they understand the consequences of not taking their medication. (Natalie, social worker, interview) ${ }^{1}$

This definition links insight to an understanding and appreciation of one's mental state and draws a connection between insight and adhering to the medical team's treatment recommendations.

Second, it is also a common practice for social workers to draw on insight to justify their interventions. If a patient is assessed as having poor insight, then interactions are shorter, while patients with more insight benefit from prolonged interactions with staff. The notion of acceptance also appears in staff's conceptualization of insight. For instance, another social worker views an individual's refusal to be hospitalized as a symptom of mental illness:

I document to protect myself legally. I also try to support the family by redirecting them to Form 2 [a request for psychiatric examination made by family members to a justice of the peace]. There are a lot of feelings of powerlessness because the patient is still very symptomatic, sick, psychotic. (Claire, social worker, interview)

Third, patients are generally perceived as having little to no insight upon admission to the inpatient unit. Being hospitalized is in and of itself a reason to doubt patients' level of insight. Their status as a "patient" is thus seen as grounds to question their capacity as knowers in relation to their mental health (Fricker, 2007). Therefore, it is difficult for staff to reconcile that a patient may refuse services while having some level of insight. Indeed, a social worker explains that their interventions are facilitated when the patient has insight:

\footnotetext{
${ }^{1}$ Participants' names (staff and patients) have been changed to protect their identities.
} 
But there's a link - because if they have a good level of insight, they will say yes to everything because they realize they need help. So ideally, in a utopian sense, that's it. It makes our job more manageable, and the therapeutic relationship is easier to develop because we're on the same page - we work together and everything. When patients - and that's a characteristic of mental illness. When insight is not present, we work against the grain, and we have to distance ourselves. (Natalie, social worker, interview)

Here the participant links insight with compliance to treatment. According to this reasoning, a patient with sufficient understanding of their mental condition would never refuse treatment. This perception shapes staff interventions and interactions with patients.

The notion of insight as acceptance follows Galasiński \& Opaliński's (2012) observations that psychiatrists often equate insight with compliance. These findings echo Diesfeld and Sjöström's (2007) claim that insight possesses a certain "interpretive flexibility" (p. 96), encompassing elements such as "awareness of illness; agreement regarding diagnosis or degree of disorder; compliance with the type or dosage of medication or willingness to remain hospitalized" (p. 96) that allow insight to be used in diverse situations. The idea of insight being related to an acceptance of hospitalization and treatment led me to construct four vignettes drawn from my interviews and observations that correlate patients' level of insight with acceptance and perceived compliance to clinical recommendations. These vignettes also help to understand which types of intervention are deployed according to the perceived level of insight, as I summarize in the table below. Each quadrant represents a different type of relationship I observed or gathered from interview data, entailing differing outcomes. While I focus on one specific example per vignette, each represents patterns of interventions and interactions that punctuate patients' journeys through the inpatient unit, with distinct epistemic and disciplinary effects.

\begin{tabular}{|c|c|}
\hline $\begin{array}{l}\text { The Difficult Patient } \\
\text { - low understanding, may refuse } \\
\text { hospitalization; } \\
\text { - insight is perceived to be low; } \\
\text { - often receives involuntary status and } \\
\text { is deemed incompetent to consent. }\end{array}$ & $\begin{array}{l}\text { The Intractable Patient } \\
\text { understands but does not accept } \\
\text { hospitalization; } \\
\text { - refuses treatment; may appeal to the } \\
\text { Consent and Capacity Board; } \\
\text { - may leave against medical advice in } \\
\text { some cases }\end{array}$ \\
\hline $\begin{array}{l}\text { The Confused Patient } \\
\text { - varying understanding of the situation; } \\
\text { - fluctuating insight; } \\
\text { - deemed unpredictable and volatile. }\end{array}$ & $\begin{array}{l}\text { The Ideal Patient } \\
\text { - understands and accepts hospitalization } \\
\text { - is seen as insightful and compliant; } \\
\text { - most likely to be moved to centre ward }\end{array}$ \\
\hline
\end{tabular}

Table 1. Relationship between insight, understanding, and acceptance. 
Low Level of Insight and Refusal of Hospitalization and Treatment: The Difficult Patient

Mrs. Latour (observed patient) was described as having very little insight. At the beginning of her hospitalization, Mrs. Latour presented herself as a medical professional and attorney. Staff found it difficult to establish a therapeutic alliance with her. Mainly due to her claims about her employment, Mrs. Latour was deemed to have no insight into her mental health situation and was characterized as being in denial about needing help. In this case, professionals must exercise patience and wait until the patient can hold a conversation before exploring treatment and discharge options (research observation notes). In such situations, psychiatrists can award or withdraw privileges to encourage good behaviour. In contrast, they can sometimes file requests to prolong an involuntary status and declare patients legally incapable of consenting to treatment. These interventions fall into the realm of infantilizing practices (Mills \& LeFrançois, 2018) because they presume patients are unable to make decisions for themselves and frame patients' conflicting perspectives as something needing to be punished and corrected, similar to how children can be seen as being "irrational, incompetent... and in need of (parental) guidance" (p. 519).

\section{Some Insight and Refusal of Hospitalization and Treatment: The Intractable Patient}

Some patients may understand their hospitalization, but staff perceives them as having less insight because they resist hospitalization or treatment. In these situations, patients have the option to appeal their involuntary status at the Consent and Capacity Board (CCB), refuse treatments, and, more rarely, leave against medical advice. This mixture of understanding and resistance punctuates Stephanie's (interviewed patient) most recent hospitalization (at the time). She received nearly 10 forced injections during a past hospitalization due to her refusal to accept hospitalization. Although she understood her need to be hospitalized on this occasion, she refused to comply with treatment:

I went on an 'everything strike.' I didn't eat, shower, or get up from my bed; I refused to speak... It was really hard for [the staff]... I was uncomfortable with what happened to me, and I didn't want to be there... They got me to do at least one thing a day, another tomorrow; it was easier like that. I stopped striking; I drank Ensure, I started drinking water again. (Stephanie, patient, interview)

Although she remained highly resistant to any attempt from staff to provide treatment, she gradually accepted her hospitalization.

An employee explains that "psychiatrists do not like going to court [the 
CCB]" (research observation notes) to justify their decision to declare a patient involuntary. Staff also report that in some instances of persistent refusal and challenging interactions with patients, some psychiatrists lower the dose of certain medications so patients cannot effectively state their case during a hearing (research observation notes). So, refusing to be hospitalized is perceived as a lack of insight. And this refusal can be punished by stifling patients' voices and their ability to advocate for themselves, which constitutes a form of epistemicide (Mills \& LeFrançois, 2018). This dynamic is also illustrative of the discrediting of individuals' experiences and perspectives due to their identity as patients (Diesfeld \& Sjöström, 2007; Fricker, 2007) through the use of medical knowledge that exercises psychiatric power to reach desired "therapeutic" outcomes.

Varying Insight and Acceptance of Hospitalization and Treatment: The Confused Patient

Stephanie had some insight and was gradually convinced to accept treatment, but other patients are sometimes described as "confused," alluding to their variable acceptance of hospitalization. While staff generally aim to discharge patients within two weeks, patients in this situation may be subjected to longer stays. This was Mrs. Tremblay's (observed patient) situation; she oscillated between understanding and confusion about why she was hospitalized. Her weeks on the unit turned into months, with staff unable to guarantee a safe discharge as they waited for her transfer to a specialized residence. This situation strained her relationships with staff to the point of reaching an impasse. She would often express that she did not know why she was still hospitalized and despair that she could not be discharged. Staff explained to her family members that her "progress" was inconsistent and unpredictable (research observation notes). Her level of insight and acceptance varied from one day to another. Before meeting patients in a similar state, staff would sometimes warn me that we should "brace ourselves" (research observation notes) for the unpredictability of the situation, drawing an association between lack of insight and resistance (Pilling et al., 2018).

High Insight and Complete Acceptance of Hospitalization and Treatment: The Ideal Patient

In the three types of patients described above, staff's emphasis on insight - or lack thereof - is evident. Engaging in therapeutic activities is necessary for patients to be discharged from hospital. If little to no insight is diagnosed, 
then therapeutic work cannot be undertaken, and patients may not be transferred to the centre ward, which is a stage that brings them closer to discharge. Insight constitutes a prerequisite for patients to authentically accept their hospitalization and allow the "real" therapeutic work to begin. The more insight a person is perceived to possess, the more they are perceived to adhere to mainstream psychiatric explanations of their hospitalization and thus to be legitimate epistemic subjects (Fricker, 2007). This position of total understanding and acceptance constitutes the fourth vignette constructed from my observations and interviews.

This "ideal patient" was embodied by Denise's (interviewed patient), who, after her second stay in the mental health unit, came to understand that she did "need help" (Denise, interview) from a psychiatrist. While she was as resistant as other patients during her first hospitalization and briefly during her second, this resistance turned into complete acceptance and engagement in the therapeutic process:

I didn't like it at first. I was really fighting it. But once I said - no, I really do need help. It took me about 12 hours to accept that I really do need help and that I need to stay, so I stayed... Everybody deals with things their own way, and what seems stupid to other people, it's not to you. You are you, and it's a problem for you. Just talk about it. And I told the psychiatrist more than I had ever told before. It took her two tries with me. I didn't talk the first time I was there. (Denise, patient, interview)

Denise's perspective regarding her hospitalization encapsulates what is expected from patients; they must understand the reasons for their hospitalization, accept it, and comply with the proposed treatment. These notions go hand in hand, in that it is impossible to truly accept treatment if there is incomplete understanding of why receiving help is deemed necessary. If patients do not fully accept their hospitalization - even though this resistance is allowed under the Mental Health Act (1990) - then they are perceived as not fully understanding and insightful.

While Danielle did not explicitly mention insight, her emphasis on realizing her need for help and understanding why she needs the supports offered at the hospital echoes professional definitions of insight. Using an evocative simile, a social worker explained how even extreme resistance to hospitalization can lead to acceptance: "we see people come in who are completely disorganized, psychotic, violent. They leave the hospital gentle as a lamb and thank us for our services. Right there, that's a success" (Lisa, social worker, interview; emphasis added). This excerpt implies that resistance and non-compliance are seen as proof or cause of lack of insight (Diesfeld \& Sjöström, 2007), and even a symptom of mental illness itself (Galasiński \& Opaliński, 2012), even though the notion of insight does not appear in diagnostic criteria.

Once patients reach this ideal state, they can engage in therapeutic activities in the centre ward. Staff may facilitate progression toward this state 
through medication (sometimes by force) and by establishing a therapeutic relationship. And, as shown above, when professionals implicitly associate insight with non-compliance, the concept may be used to justify coercive interventions to help develop or restore insight - and thus compliance - in patients (Pilling et al., 2018). These actions compel patients to understand the necessity of hospitalization. Because insight is dynamic, a patient's level of insight may change many times during their hospitalization. Thus, privileges can be revoked or reinstated; patients can be transferred back to the south ward if their mental state deteriorates and they are assessed as needing more surveillance.

In this section, I analyzed how insight is defined and deployed by staff members. My analysis demonstrates that insight is a crucial concept used in upholding psychiatric norms of ideal patienthood. Patients must accept their hospitalization and reframe their situation in a way that adheres to psychiatry's view. In the following section, I discuss key dynamics and implications of this analysis.

\section{Discussion}

Regarding applications of insight, staff participants believe that lack of insight is a symptom of mental illness and adjust their interactions with patients until they observe sufficient levels of insight and compliance. When patients begin accepting their hospitalization and the medical team's treatment recommendations, they are perceived as having regained insight and stabilized mental illness. These results point to the possibility of an inverse relationship between the level of insight and length of hospital stay. Insight plays a role in orienting interventions despite problems related to its “interpretive flexibility" (Diesfeld \& Sjöström, 2007, p. 96). Diluting the meaning of insight by associating various attitudes and behaviours with the concept raises conceptual and practical issues in providing mental health services. Conceptually, basing clinical definitions - even partially - on a concept that may mean different things to different professionals does not provide solid foundations for interventions.

It is also interesting to note that while patients did not speak of insight per se, their interview narratives implicitly refer to notions of refusal, understanding, acceptance, and collaboration that professionals articulate explicitly. These notions are seen as markers of good insight. Patients often frame their hospitalization experiences in a manner that shows progression from their initial protest and resistance toward an eventual acceptance of their hospitalization and psychiatry's explanation of their mental difficulties. When I asked patient participants if they had appealed their involuntary status, many answered that they had not. While the Mental Health Act (1990) 
delineates a patient's right to appeal involuntary hospitalization and judgments of their inability to consent, this practice was discouraged and even punished at times by mental health practitioners.

Moreover, if patients do not adhere to the medical model, then psychiatry is unable to understand their experiences and ways of making sense of their situations. Patients' refusal of hospitalization, whether in a voluntary or involuntary context, is seen as a routine aspect of hospitalization and an obstacle to be overcome. Insight plays a key role in framing dissent as a symptom or consequence of mental illness. Interventions are put in place to help individuals become "more insightful" and accept their hospitalization. These observations support Pilling et al.'s (2018) conclusions that insight is often used as a tactic in "delegitimizing disagreement" (p. 195). Indeed, staff's use of expressions such as "getting a patient's side of the story" seems to place patients in a position of testimonial injustice (Fricker, 2007); as my four vignettes indicate, only the ideal insightful patient who expresses maximal understanding and acceptance is heard, understood, and given credence as an epistemic agent.

As I have demonstrated, patients' testimonies can be viewed as a symptom of their diagnosis. Help is conditional on accepting and adhering to psychiatry's explanation of mental distress. These elements confirm psychiatry's status as the principal model of explaining mental distress (Rimke, 2018; Roy et al., 2017). The extent to which patients shared psychiatry's vision of their situation demonstrates its epistemic hold on human suffering and constitutes a key feature of the normative psychiatric subject. In this context, carceral notions of punishment remain a routine aspect of psychiatric interventions (Ben-Moshe, 2020). Indeed, formal (e.g., privilege system, forced injections) and informal (e.g., adjusting medications to punish resistant patients) mechanisms show the persistence of a carceral logic in the mental health unit.

\section{Conclusion: Moving Beyond Reform and Toward Abolition}

In this paper, I contribute to critical perspectives on mental health services by exploring the uses of insight in a psychiatric inpatient unit. This objective leads me to discuss the disciplinary and epistemic effects of insight. While insight - or lack thereof - is not a symptom of mental illness per se, uses of insight by mental health professionals go beyond clinical definitions and threaten patients' right to be comprehended and treated as credible epistemic subjects (Fricker, 2007). While the concept of insight was not a primary concern when I initiated the study (it focused more broadly on contemporary patienthood), insight emerged in the data as an element that influences how individuals incorporate the patient role in their own lives, following mental health professionals' use of it in orienting their interventions. 
The analysis presented here should be understood as exploratory, warranting the need for further research on insight and its uses in mental health interventions. Notions of understanding, acceptance, compliance, and at times a positive view of services all seem to be associated with insight. In cases in which perceived low insight is associated with poor therapeutic "progress," patients could be subjected to coercive measures to restore insight. As Tate (2019) stresses, to alleviate this problem alternative perspectives to dominant psychiatric discourse must be rendered legitimate to allow patients to be conceived as "equal epistemic agents" (p. 98).

The most poignant results from this study, however, relate to the use of coercive and punitive methods to restore insight and compliance. There is an urgent need for further studies that deeply reflect on the carceral logic deployed in mental health services, both inside and outside institutions (Fabris, 2011; Fabris \& Aubrecht, 2014), and highlight the necessity of an abolitionist analysis and strategy (Ben-Moshe, 2014, 2020). Forms of oppression such as racism, sexism, and classism influence individuals' experiences in psychiatric services and may lead to marginalized groups' increased rates of institutionalization (Ben-Moshe, 2020; Kilty \& Dej, 2018). In this sense, my results point toward the possible existence of a "white insight" that serves normative ideals useful to white supremacy and other confluent forces (Joseph, 2015). Future critical studies on insight must consider these elements to promote a social justice-oriented view of mental health and illness that locate white, patriarchal, and sane supremacy at the heart of psychiatric interventions.

\section{Acknowledgements}

I want to thank my research participants for generously sharing their experiences with me. The data analyzed here were collected with the support of a SSHRC doctoral scholarship (2014-2017). I would also like to acknowledge the contribution of anonymous reviewers who provided constructive comments. Finally, I would like to thank Studies in Social Justice editor Nancy Cook for her attentive reading of the final draft of this manuscript.

\section{References}

Anthony, W. A. (1993). Recovery from mental illness: The guiding vision of the mental health service system in the 1990s. Psychosocial Rehabilitation Journal, 16(4), 11-23.

Beck-Sander, A. (1998). Is insight into psychosis meaningful? Journal of Mental Health, 7(1), 25-34. 
Ben-Moshe, L. (2014). Alternatives to (disability) incarceration. In L. Ben-Moshe, C. Chapman \& A. C. Carey (Eds.), Disability incarcerated: Imprisonment and disability in the United States and Canada (pp. 255-272). Palgrave Macmillan.

Ben-Moshe, L. (2020). Decarcerating disability: Deinstitutionalization and prison abolition. University of Minnesota Press.

Braun, V., \& Clarke, V. (2006). Using thematic analysis in psychology. Qualitative Research in Psychology, 3(2), 77-101.

Chapman, C., \& Withers, A. J. (2019). A violent history of benevolence. University of Toronto Press.

Conrad, P. (2005). The shifting engines of medicalization. Journal of Health \& Social Behavior, 46(1), 3-14.

Crichton, P., Carel, H., \& Kidd, I. J. (2017). Epistemic injustice in psychiatry. BJPsych Bulletin, 41(2), 65-70.

David, A. S. (1990). Insight and psychosis. The British Journal of Psychiatry, 156(6), 798-808.

Deegan, G. (2003). Discovering recovery. Psychiatric Rehabilitation Journal, 26(4), 368-376.

Diesfeld, K., \& Sjöström, S. (2007). Interpretive flexibility: Why doesn't insight incite controversy in mental health law? Behavioral Sciences \& the Law, 25(1), 85-101.

Fabris, E. (2011). Tranquil prisons: Chemical incarceration under community treatment orders. University of Toronto Press.

Fabris, E., \& Aubrecht, K. (2014). Chemical constraint: Experiences of psychiatric coercion, restraint, and detention as carceratory techniques. In L. Ben-Moshe, C. Chapman \& A. C. Carey (Eds.), Disability incarcerated: Imprisonment and disability in the United States and Canada (pp. 185-199). Palgrave Macmillan.

Foucault, M. (1979). Discipline and punish: The birth of the prison. Vintage Books.

Foucault, M. (2006). Psychiatric power: Lectures at the Collège de France, 1973-74. Palgrave Macmillan.

Fricker, M. (2007). Epistemic injustice: Power and the ethics of knowing. Oxford University Press.

Galasiński, D., \& Opaliński, K. (2012). Psychiatrists' accounts of insight. Qualitative Health Research, 22(11), 1460-1467.

Goffman, E. (1968). Asylums: Essays on the social situation of mental patients and other inmates. Anchor Books/Doubleday.

Guibet Lafaye, C. (2015). Représentations de la maladie mentale et recours à la contrainte. Psychiatrie \& Violence, 14(1). https://www.erudit.org/fr/revues/pv/2015-v14-n1pv02896/1039168ar/

Hamilton, B., \& Roper, C. (2006). Troubling 'insight': Power and possibilities in mental health care. Journal of Psychiatric \& Mental Health Nursing, 13(4), 416-422.

Joseph, A. J. (2015). Beyond intersectionalities of identity or interlocking analyses of difference: Confluence and the problematic of 'anti'-oppression. Intersectionalities: A Global Journal of Social Work Analysis, Research, Polity, \& Practice, 4(1), 15-39.

Kelly, C., \& Chapman, C. (2015). Adversarial allies: Care, harm, and resistance in the helping professions. Journal of Progressive Human Services, 26(1), 46-66.

Khoury, E., \& Rodriguez del Barrio, L. (2015). Recovery-oriented mental health practice: A social work perspective. British Journal of Social Work, 45(S1), i27-i44.

Kilty, J. M., \& Dej, E. (Eds.). (2018). Containing madness: Gender and 'psy' in institutional contexts. Springer.

Klein, A., Guillemain, H., \& Thifault, M. C. (2018). La fin de l'asile? Histoire de la déshospitalisation psychiatrique dans l'espace francophone au xxe siècle. Presses universitaires de Rennes.

Konstantakopoulos, G. (2019). Insight across mental disorders: A multifaceted metacognitive phenomenon. Psychiatriki, 30(1), 13-16.

Kristensen, G. K., \& Ravn, M. N. (2015). The voices heard and the voices silenced: Recruitment processes in qualitative interview studies. Qualitative Research, 15(6), 722-737.

Laplantine, F. (2010). La description ethnographique. Armand Colin. 
LeBlanc, S., \& Kinsella, E. A. (2016). Toward epistemic justice: A critically reflexive examination of 'sanism' and implications for knowledge generation. Studies in Social Justice, 10(1), 59-78.

Madison, D. S. (2019). Critical ethnography: Method, ethics, and performance. Sage Publications.

Marková, I. (2005). Insight in psychiatry. Cambridge University Press.

Marková, I., \& Berrios, G. E. (1995). Insight in clinical psychiatry revisited. Comprehensive Psychiatry, 36(5), 367-376.

Mental Health Act, R.S.O. 1990, c. M.7. https://www.ontario.ca/laws/statute/90m07

Mills, C., \& LeFrançois, B. A. (2018). Child as metaphor: Colonialism, psy-governance, and epistemicide. World Futures, 74(7/8), 503-524.

Mintz, A. R., Dobson, K. S., \& Romney, D. M. (2003). Insight in schizophrenia: A metaanalysis. Schizophrenia Research, 61(1), 75-88.

Perron, A., Fluet, C., \& Holmes, D. (2005). Agents of care and agents of the state: Bio-power and nursing practice. Journal of Advanced Nursing, 50(5), 536-544.

Pilling, M., D., Daley, A., Gibson, M. F., Ross, L. E., \& Zaheer, J. (2018). Assessing 'insight', determining agency and autonomy: Implicating social identities. In J. M. Kilty \& E. Dej (Eds.), Containing madness: Gender and 'psy' in institutional contexts (pp. 191-213). Springer.

Procknow, G. (2018). (Dis)arming the madman: Sane supremacy and the Second Amendment. Disability \& Society, 33(7), 1165-1169.

Rimke, H. (2018). Sickening institutions: A feminist sociological analysis and critique of religion, medicine, and psychiatry. In J. M. Kilty \& E. Dej (Eds.), Containing madness: Gender and 'psy' in institutional contexts (pp. 15-39). Springer.

Rimke, H., \& Brock, D. (2012). The culture of therapy: Psychocentrism is everyday life. In D. Brock, A. Martin, R. Raby \& M. Thomas (Eds.), Power and everyday practices (pp. 182202). Nelson Education Ltd.

Rivest, M.-P. (2017). Etre "patiente » aujourd'hui: Entre assujettissement normatif et résistances à l'imposition d'une carrière. Regards croisés sur des expériences au sein d'institutions contemporaines en santé mentale [Unpublished doctoral dissertation]. University of Ottawa.

Rivest, M.-P., \& Moreau, N. (2015). Between emancipatory practice and disciplinary interventions: Empowerment and contemporary social normativity. British Journal of Social Work, 45(6), 1855-1870.

Roberts, M. (2005). The production of the psychiatric subject: Power, knowledge and Michel Foucault. Nursing Philosophy, 6(1), 33-42.

Roy, M. (2019). Les conduites éthiques et le rétablissement: Analyse d'une revue de littérature en travail social. Nouvelles Pratiques Sociales, 30(2), 234-248.

Roy, M., Rivest, M.-P., \& Moreau, N. (2017). The banality of psychology. Social Work, 62(1), 86-88.

Sealy, P., \& Whitehead, P. C. (2004). Forty years of deinstitutionalization of psychiatric services in Canada: An empirical assessment. Canadian Journal of Psychiatry, 49(4), 249-257.

Segarra, R., Ojeda, N., Pena, J., Garcia, J., Rodriguez-Morales, A., Ruiz, I., Hidalgo, R., Buron, J. A., Eguiluz, J. I. I., \& Gutierrez, M. (2012). Longitudinal changes of insight in first episode psychosis and its relation to clinical symptoms, treatment adherence and global functioning: One-year follow-up from the Eiffel study. European Psychiatry, 27(1), 43-49.

Tate, A. J. M. (2019). Contributory injustice in psychiatry. Journal of Medical Ethics, 45(2), 97 100.

Thomas, J. (1993). Doing critical ethnography. Sage Publications. 